\title{
Conceptualising work-integrated learning to support pre-service teachers' pedagogic reasoning
}

\section{Lee Rusznyak}

School of Education, University of the Witwatersrand, Johannesburg, South Africa

Lee.Rusznyak@wits.ac.za

https://orcid.org/0000-0002-6835-8215

\section{Carol Bertram}

School of Education, University of KwaZulu-Natal, Pietermaritzburg, South Africa

BertramC@ukzn.ac.za

https://orcid.org/0000-0002-2961-5645

(Received: 11 March 2021; accepted: 13 May 2021)

\section{Abstract}

Much South African research suggests that work-integrated learning (WIL) experiences of pre-service teachers are uneven. Their learning depends heavily on the functionality of the school and on the presence and commitment of the mentor teacher. Even then, mentor feedback tends to focus on generic comments on classroom routines rather than providing an account of their teaching practices. In this conceptual paper, we draw on a range of literature and studies to argue that the value of WIL would be greatly enhanced if pre-service teachers and their mentors discuss both the visible classroom routines and the less visible reasoning that inform the pedagogic choices that teachers make. This focus on pedagogic reasoning could foreground both the principled knowledge base that teachers need, as well as the contextual responsiveness and ethical orientations needed to become a specialised knower within the teaching profession. WIL therefore needs to provide preservice teachers with explicit, structured opportunities to consider how the teachers they observe enact their teaching and why. They also need to articulate the pedagogic choices they make in the design and delivery of their own lessons. We argue that structuring WIL as a space in which to recognise and engage in forms of pedagogic reasoning addresses some of the challenges of the uneven quality of student learning identified in research on WIL in the South African context.

Keywords: pedagogic reasoning, pre-service teacher, teacher education, teaching practice, work-integrated learning, knower, gaze, Legitimation Code Theory 


\section{Introduction}

Learning to teach should not be left to chance. Ideally, work-integrated learning (WIL) provides pre-service teachers with opportunities to observe the lessons of practising teachers and discuss them. It should give them opportunities to plan, teach, and reflect on their own lessons and obtain feedback on their own teaching. Working alongside experienced teachers is expected to enable students to learn "the process of acting and thinking wisely in the immediacy of classroom life: making split-second decisions; choosing among alternative ways to convey subject matter; interacting appropriately with an array of students and selecting and focusing on particular dimensions of classroom problems" (Cochran-Smith \& Lytle, 1999, p. 266, italics added). However, having pre-service teachers spend the required amount of time in classrooms does not necessarily result in relevant and meaningful learning experiences. While some of them report having rich and rewarding learning opportunities during WIL, the learning experiences for others fall short of their potential value. While students easily notice teachers' classroom routines and visible actions, they do not always notice or understand the many decisions and judgement calls teachers make in their daily teaching practices and are often unaware of their knowledge, intentions, and thinking processes (Lortie, 1975). Pre-service teachers tend to underestimate the complexity of organising learning opportunities in the lessons they observe (Hammerness et al., 2005). One reason for this is that practicing teachers tend to "focus more on 'doing teaching' rather than on explicating associated pedagogic reasoning" to the student teachers they mentor (Berry et al., 2008, p. 1271). Since teaching is an embodied practice, WIL undoubtedly has value for prospective teachers' acquisition of different knowledge from that which is available through coursework. However, if pre-service teachers are to understand teaching as a knowledgebased reasoned practice, WIL needs to be structured so that pre-service teachers observe more than the performance dimensions of teaching as they did during their own schooling. Part of becoming informed responsive practitioners requires that pre-service teachers understand the choices teachers make from a range of options.

In this paper, we make a conceptual argument that the quality of learning during WIL would be strengthened if both pre-service and mentor teachers recognise that teachers' decisions about their planning and classroom action are informed by principled knowledge, contextual priorities, material conditions, and ethical orientation of the practice. Viewed this way, WIL can be constructed as a space in which students can engage in pedagogic reasoning. "Pedagogic reasoning", a term introduced by Shulman (1987, p. 13), describes how teaching "begins with an act of comprehension, continues with a process of reasoning, culminates in performances of imparting, eliciting, involving, or enticing, and then is thought about some more." We argue here that a key challenge for Initial Teacher Education (ITE) programmes is to structure WIL to value both the thinking work and the performance dimensions of teaching.

We develop the argument first, by reviewing briefly how the benefits of WIL are constructed in South African policy and in the literature as providing opportunities for knowledge acquisition and embodied learning experiences. We then review South African studies on 
WIL that point to the uneven nature of pre-service teachers' learning experiences. We go on to argue why a pedagogic reasoning approach to WIL addresses some of the concerns and challenges raised in research studies about WIL. We conclude with three practical ways in which we believe that pedagogic reasoning can be foregrounded in WIL along with a consideration of its limitations.

\section{The value of WIL in ITE: A policy perspective}

The Minimum Requirements for Teacher Education Qualifications (MRTEQ) policy (Department of Higher Education and Training (DHET), 2015, p. 11) that governs teacher education in South Africa regards teaching as "a complex activity that is premised upon the acquisition, integration and application of different types of knowledge practices." It specifies that ITE curricula must ensure that pre-service teachers have access to different types of knowledge. It offers an account of what constitutes disciplinary, foundational, practical, pedagogic, and situational learning. The design of ITE curricula must ensure that pre-service teachers have access to a stipulated "knowledge mix" of credits allocated to each of these different types of learning (p. 15). When ITE programmes focus on providing opportunities for students to access the different kinds of knowledge needed, WIL is conceptualised as giving students opportunities to develop practical and situational knowledge. These knowledge types may be acquired partially through practice-focused activities in coursework but are thought to be enriched through noticing and making sense of the complexity of classroom life in authentic school contexts.

MRTEQ presents three benefits of WIL. First, WIL enables pre-service teachers to accumulate "concrete" classroom experience. Policy declares that "time spent in the actual workplace is very important" (DHET, 2015, p. 18) and specifies how much time prospective teachers need to spend in school-based placements during their ITE. Second, WIL provides pre-service teachers with opportunities to engage in "practical learning", regarded by policy as "an important condition for the development of tacit knowledge which is an important component of learning to teach" (p. 10). Pre-service teachers are said to accumulate this knowledge by observing and reflecting on lessons taught by others, as well as gain in preparing, teaching, and reflecting on their own lessons. Third, WIL is valued because it contributes to students" "situational learning." Policy stresses the importance of exposing students to "varied and contrasting contexts of schooling in South Africa" (p. 18). When WIL is conceptualised primarily as an opportunity for pre-service teachers to accumulate experiential forms of knowledge, the focus of student teaching is on doing and less on making sense of what they observe and why they do what they do.

MRTEQ sets up policy conditions to provide pre-service teachers with such a knowledge base and suggests that the "fusing together of different kinds of knowledge" should happen in the moments of practice (DHET, 2015, p. 9). However, our review of South African research suggests that this "fusing" does not happen spontaneously. Developing students' teaching competence requires something more than curricula that provide opportunities for pre-service teachers to acquire various bodies of knowledge. 


\section{The quality of student learning during WIL}

In this section we review research that suggests that South African pre-service teachers do not always experience meaningful opportunities for professional growth, even when school-based practicum sessions are well-organised and supervised. We identified and surveyed South African studies on WIL from 2002 onwards. Many empirical papers on WIL analyse stakeholder responses to surveys, questionnaires, individual interviews, or focus group discussions (e.g., Bertram et al., 2013; Du Plessis et al., 2010; Matoti \& Odora, 2013; Moodley et al., 2018). Together, this large body of substantive research has generated indepth and plentiful description of the beliefs, perceptions, and experiences of pre-service teachers, mentor teachers, and university-based teacher educators about the affordances and limitations of work-based learning. Some studies use these insights to suggest ways of improving communication to facilitate better working partnerships between different stakeholders (see Moosa, 2018; Robinson, 2015; Silbert \& Verbeek, 2016). For the purposes of this paper, we focus on empirical studies that point to the uneven quality of student learning during WIL. We then show how concerns raised provide a gap for a different approach to WIL that foregrounds the reasoning of pre-service teachers in practice.

Several comparative studies that focus on the logistical arrangements of WIL have shown huge variation in the conceptualisation and organisation of work-integrated learning (see Council on Higher Education, 2010; Deacon, 2016; Menkveld et al., 2008; Robinson, 2015). The national Initial Teacher Education Research Project that analysed ITE curricula offered by five higher education institutions found that work-integrated learning "exhibited substantial variations between universities in terms of duration, organisation, the quality and content of learning experiences and the form and nature of assessment" (Deacon, 2016, p. 11). Such unevenness poses a "significant challenge to quality" in the sector (Council on Higher Education, 2010, p. 94). The unevenness is encountered not only in terms of different logistical arrangements, but also in what is valued by assessment rubrics, the demands of lesson planning, and the nature of interactions between student teachers and mentor teachers.

Several studies on WIL have raised concern that pre-service teachers gain little access to the reasoning underpinning the decisions mentor teachers make in the design of the lessons they teach, nor do students always receive meaningful feedback on those lessons they teach themselves. Studies have reported high levels of teacher absenteeism during WIL (Gravett \& Jiyane, 2019; Moodley et al., 2018) and this means that students are often left largely to their own devices in classrooms. Students are told to figure out their lessons with little guidance or they receive little feedback on their lessons (Rusznyak \& Walton, 2017). Although preservice teachers may get ample opportunities to observe and teach lessons when supervising teachers are absent, experience alone does not guarantee that students will or can access the rationale that underpins teaching choices in action (see Gravett \& Ramsaroop, 2015; Gravett et al., 2011; Reeves \& Robinson, 2014). Even when structured feedback is provided to students, its potential for enabling them to access teachers' thinking is not always realised. A study on the mentoring of part-time Postgraduate Certificate in Education (PGCE) students showed that most of the 19 teachers in the study received either generic feedback from 
mentors or very little feedback at all (Mukeredzi et al., 2015). Similarly, a study by Borello (2019) on mentorship of pre-service teachers in a South Africa learnership programme showed how conversations between student teachers and three experienced teachers seldom moved beyond providing encouragement and general classroom tips. The feedback focused on performance dimensions of practice and provided little access to teachers' reasoning behind that which informs what they do and why. Without meaningful conversations with mentor teachers about the lessons they have observed or are to prepare, pre-service teachers do not necessarily learn why some decisions may be appropriate in some contexts but not in others.

University-based expectations, embodied in lesson planning guidelines and prompts for reflection, focus students' attention on particular aspects of teaching practices. These guidelines can convey that teaching is just a routine technical endeavour or they may be designed to create opportunities for articulating principled and contextually responsive reasoning. For example, when lesson planning requires little more than a link to curriculum and written lesson steps, opportunities for students to justify their teaching choices are missed (Rusznyak \& Walton, 2011). Similarly, prompts that pre-service teachers use to reflect on their teaching tend to direct their attention to observable and experiential aspects of classroom activity (see Evans 2019; Rembe et al., 2016). Seldom do these prompts ask students to think about logics that inform teacher decision-making for/in their lessons, and how concepts drawn from their university coursework may help them to interpret critical incidents in the classroom. In another small-scale case study, Langsford (2020) found that there was a large disparity between the ways in which newly qualified teachers recruited formal concepts to analyse and evaluate the teaching they observed in a recorded lesson.

Assessment rubrics for observation of teaching practice are another way of transmitting messages to pre-service teachers about what matters in their teaching. These rubrics may hinder the development of their reasoned judgement if teaching is portrayed as a set of routines that pre-service teachers must enact regardless of the demands of the content they teach, the needs of learners, and the possibilities in the context of their classroom. For example, a criterion that always requires group work in a lesson suggests that there are some teaching strategies that always work, rather than suggesting that teaching strategies should be selected because of their value in achieving the aims of a particular lesson. When the assessment rubrics for student teaching are designed as checklists, a technical, normative approach to understanding teaching is advanced (Rusznyak \& Bertram, 2015), rather than emphasising the central role of teacher judgement (Biesta, 2015). Furthermore, some rubrics tend to use levels of competence that specify vague indicators of achievement (such as 'excellent' or 'very good'). If the assessment of students' developing teaching competence focuses on personal dispositions and observable classroom action, the assessment of student teaching may easily result in highly subjective judgments. The message transmitted to preservice teachers is that effective teaching is routine, and assessment of its quality is arbitrary. Opportunities to consider both the reasoning and performance dimensions of teaching as grounds for achievement are minimised when assessment rubrics are structured in this way. 
Thus, from this body of literature, we conclude that the WIL experiences of pre-service teachers are uneven and that mentor teachers are often absent or do not always provide meaningful feedback on students' practice. Assessment rubrics and lesson planning guidelines tend to focus on teacher dispositions and observable action rather than on the reasoning underpinning their judgements in practice.

We now move on to examining the concept of pedagogic reasoning and develop our argument for how WIL can develop this reasoning more explicitly.

\section{Developing pedagogic reasoning}

By the time prospective teachers qualify, they should have learnt to "reason soundly about their teaching as well as to perform skilfully" (Shulman, 1987, p. 13, emphasis added). The South African Council of Educator's (SACE) Professional Teaching Standards reflect this expectation in its requirement that "teachers [should] make thoughtful choices about their teaching that lead to learning gains for all learners" (SACE, 2019, p. 10). Sound reasoning requires "both a process of thinking about what they are doing and an adequate base of facts, principles and experiences from which to reason" (Shulman, 1987, p. 13, emphasis added). Shulman (1987) proposed that seven types of teacher knowledge are needed for effective teaching. He identified these as subject knowledge, general pedagogical knowledge, knowledge of the curriculum, pedagogical content knowledge, knowledge of learners, knowledge of educational contexts, and knowledge of educational purposes and values. Since his initial proposal, these categories have been contested and redefined (see Ball et al., 2008; Grossman, 1990; Verloop et al., 2001). However, having access to these different bodies of knowledge is not enough to be able to enact them in practice.

Loughran (2019, p. 526) suggested that pedagogic reasoning is the "thinking that underpins informed professional practice." Horn (2010, p. 237) used pedagogic reasoning to analyse conversations between teachers in which episodes of pedagogic reasoning are defined as "moments in teachers' interaction when they describe issues in, or raise questions about, teaching practice, and [in which] these descriptions are accompanied by some elaboration of reasons, explanations, or justifications." A pedagogic reasoning approach suggests that the grounds on which teachers make choices are not arbitrary or idiosyncratic. Rather, the grounds for their choices and actions are "supported by ethical, empirical, theoretical or practical principles" (Shulman, 1987, p. 13). In this paper we draw on the work of Duffy (2005) and Morrow (2007) to present pedagogic reasoning as a specialised way of thinking in which teachers draw on different kinds of knowledge as well as different types of knowledge within contextual realities to make ethical, appropriate, and responsive choices that organise opportunities for learning.

\section{The affordances of a pedagogic reasoning approach to WIL}

In the sections that follow, we argue that a pedagogic reasoning approach to WIL addresses some of the concerns and challenges raised in research studies about WIL. First, we critique 
approaches to WIL that disregard the knowledge base for teaching and disregard approaches that underestimate the role of teachers as knowing, thinking practitioners. We suggest that a pedagogic reasoning approach provides a socialisation into communal aspects of practice as well as enabling students to develop their own patterns of thinking about planning, teaching, and assessing. Second, we consider the extent to which the expectations of pre-service teachers during WIL bring theoretical knowledge into dialogue with the experiential and contextual knowledge gained during their practical learning. We then consider the extent to which a pedagogic reasoning approach encourages students to be responsive to the demands of the contexts while maintaining the goals of the practice. Third, we consider how a pedagogic reasoning approach in the design of WIL could build coherence and connection between different parts of ITE curricula.

\section{A pedagogic reasoning approach to WIL embraces both knowledge and knowers}

In this section we consider the limitations of approaches to WIL that leave pre-service teachers to develop their own individualised, personal approaches to their teaching as well approaches to WIL that require the indiscriminate and mechanical application of scripts, routines, or strategies. We show how neither of these approaches to WIL prepares students to be teachers whose practices are informed by principled knowledge and who develop an ethical and moral commitment to teaching.

Unevenness in the quality of student learning is exacerbated by approaches to WIL that regard students' dispositions and experiential learning as an entirely sufficient basis for their practice. When ITE programmes focus primarily on "the person of the teacher" (Korthagen, 2017, p. 398) teaching practices are steered by students' personal mission and their demonstration of teacher dispositions such as kindness, fairness, and honesty. While acknowledging that these dispositions enhance the capacity of teachers to work productively with children, these dispositions alone do not enable them to make complex concepts accessible to diverse learners. Approaches to WIL arising from this conception of teacher preparation prioritise "reflectively acquired self-knowledge" (Carr, in Hirst \& Carr, 2005, p. 625). Approaches to WIL in this tradition may encourage pre-service teachers to articulate a personal philosophy of teaching before they have access to scholarly perspectives on teaching and learning (see Dorovolomo, 2004). Practical knowledge develops through reflection on teaching, argued Carr (in Hirst \& Carr, 2005), Korthagen (2017) and Schön (1987).

Korthagen, for example, argued that teachers' behaviour in the classroom is shaped by "a complex mix of cognitive, affective and motivational sources" (2017, p. 390). Their position acknowledges the importance of personal attributes but obscures the role of principled knowledge in informing teachers' thinking, situational judgement, and subsequent action.

The onus for self-development requires that pre-service teachers figure out tacit knowledge for themselves. In other words, the criteria for what constitutes effective practice is deemed to be self-evident. Even beginner pre-service teachers are expected to select instinctively those aspects of classroom practice worthy of deeper personal reflection. Those who figure it out for themselves may do well, but those who cannot access the implicit knowledge and criteria of what matters are left to struggle (Österling, 2021). When there seems to be no underlying 
logic informing practice, students easily and uncritically revert to "delivering education in the same manner in which they were taught" (Borg, 2004, p. 274) or adopt prevalent practices irrespective of their effectiveness. Because of its highly individualised nature, there are no substantive grounds upon which some teaching practices can be regarded as more appropriate than others. Any attempt at justifying choices could be equally valid irrespective of the quality of learning experiences created.

Learning to teach without access to shared ethical orientation, a knowledge base, or understanding of what constitutes effective practice reduces practice to a collection of arbitrary actions. Whereas the individualised approach dismissed the importance of knowledge, teaching conceptualised as a technical activity dismisses teachers as knowing and thinking practitioners who manage learners, learning environments, and the knowledge to be learnt. In a view of teaching as the routine implementation of protocols, teacher thinking is irrelevant, and actions are mechanically invoked irrespective of the needs of learners, the opportunities and limitations of the context, or what the learning situation demands. In this sense, the protocols to be implemented are independent of the discretion of the teacher in context. This approach to WIL requires students to apply approved protocols in practice, and effective teaching is judged by the presence of the stipulated strategies, routines, and resources. Effectively, the teacher as a knowledgeable, thinking, responsive practitioner is ignored (Hoban, 2005).

In contrast to the two approaches described above, developing capacity for pedagogic reasoning requires that future teachers come to understand that teachers' "decisions about what to do are not appropriately rooted in personal preferences or experiences but are instead based on professionally justified knowledge and on the moral imperatives of the role" (Ball \& Forzani, 2009, p. 500). A pedagogic reasoning approach to WIL acknowledges that principled knowledge informs judgement in practice (Shalem, 2014). In addition, it recognises teachers as knowing, thinking practitioners who shape and enact practices in contextually responsive ways. This position can be further developed by drawing on concepts from Legitimation Code Theory (LCT), a sociological approach that is used to research, analyse, and transform practices (Maton, 2014). The Specialization dimension of LCT is based on a premise that all practices are orientated towards a particular part of the world, have a relation to knowledge, and are enacted by social actors. While knowledge has its own structures and powers to shape the identity, dispositions, and consciousness of social actors, they, too, can transform practices. Messages about what matters can be transmitted and received through "interactions with significant others" (Maton, 2014, p. 185). These "significant others" could be, for example, theoretical concepts, feedback from more expert or experienced practitioners, policy documents, studies on great works, or examples of exemplary works themselves. Although students bring diverse educational experiences, dispositions, and social identities into their studies, they become knowers as they acquire a specialised "gaze" through these interactions (Bernstein, 2000, p. 165). Gaze refers to ways of recognising and realising what matters in how practice is enacted and how achievement is recognised. A gaze enables practitioners to become "knowers" who can distinguish the significant from the arbitrary in their respective fields of practice (Maton, 2016, p. 91). 
Although knowers construct knowledge, they do so "not under conditions or in ways entirely of their own making, and not entirely alone" (Maton, 2014, p. 10). Through their ITE curricula, pre-service teachers interact extensively with many of these significant others during coursework and during WIL. Significant interactions that contribute to the formation of a gaze may be interactions with concepts, through opportunities for pre-service teachers to study classroom artefacts and exemplary examples of practice, as well as their participation in learning activities, responses to assessment tasks, and engagement with feedback. Criteria about what matters can also take place through socially mediated interactions, such as with mentor teachers during WIL. Through interactions such as these, pre-service teachers become more specialised knowers as they consolidate and deepen their understanding of salient aspects of practice.

Interactions with concepts, coursework tasks, practitioners and feedback enable novices to develop more specialised ways of seeing and thinking in practice. Unlike an individualised approach, it is not expected that students already know how to teach and can figure it out for themselves. A conceptualisation of WIL as part of their socialisation into teaching practices also privileges developing pre-service teachers as thinking knowers whose decisions are shaped by principled positions and subject to professionally established standards (SACE, 2019). During WIL, they engage extensively with university documentation (such as lesson planning guidelines, prompts for reflection, and assessment rubrics) which potentially transmit criteria about what matters for achievement (Rusznyak \& Bertram, 2015). The quality of student learning during WIL is thus dependent on the extent to which the messages about what counts as worthwhile are explicit and accessible to students. When the assessment of competent teaching acknowledges thoughtful consideration of options and a reasoned justification of action, opportunities for students to articulate their reasoning in practice are created.

\section{Pedagogic reasoning approach in WIL enables students to consider principled teaching in contextually responsive ways}

One of the most challenging questions in relation to conceptualising WIL is how to enable students to participate in a "process of 'dialogue' with the situation" in authentic teaching contexts (Verloop et al., 2001, p. 443). Given that teaching is always embodied in a context, some approaches to WIL prepare students for the conditions in particular school contexts. Others equip them with the conceptual tools to be adaptive across diverse school contexts. Morrow's (2007) distinction between the formal and material elements of teaching is useful here. He argued that teaching is "the practice of organising systematic learning" (p. 101). This formal definition transcends the context in which the teaching happens. If someone is not organising systematic learning, they are not teaching. Knowledgeable, skilled, and ethical teachers seek to organise systematic learning within the possibilities of their contexts, using the current curriculum, being aware of the diverse learners, and using the entire range of available resources. The material elements of an object or practice are those components that can change, without it "ceasing to be an action or object of a particular kind" (Morrow, 2007, p. 98). Morrow further argued that ITE programmes need to make it clear to student teachers 
that teaching is a practice that "centres around the design of learning programmes that foster the gradual development of competences that cannot be learnt in an instant" (p. 14).

One approach to WIL is to identify current contextual realities and focus the preparation of pre-service teachers on those sets of conditions. This perspective assumes that the realities of different school contexts are so significant that ITE programmes should prepare pre-service teachers explicitly for specific conditions or contexts. An example of this is a view that learning to teach in rural schools in South Africa is a fundamentally different practice that has nothing in common with how teachers for urban schools should be prepared (de Lange et al., 2014). The specificities of the context of rural schools are well documented. Schools often have few learning resources such as textbooks or computers, minimal services such as running water and electricity, and are in communities with high poverty households that are often headed by grandmothers or children, and that have high levels of unemployment (Nelson Mandela Foundation, 2005). While pre-service teachers may seem to cope more readily with contexts for which they have been specifically primed, Morrow's ideas illuminate the pitfalls of focusing too acutely on the specificities of the immediate needs of a teaching context so that the material elements of teaching are foregrounded at the expense of the formal elements. When teacher preparation is so focused on the specificities of a current context (or, for that matter, on the current national curriculum iteration), pre-service teachers may not necessarily have access to abstract principles that enable them to imagine and enact quality teaching when those material elements change.

In contrast, other research considers the importance of preparing pre-service teachers for diverse contexts (see Amin \& Ramrathan, 2009; Nkambule \& Mukeredzi, 2017; Ramsaroop, 2016; Rusznyak \& Walton, 2017) and how to prepare them for such diversity (see Mazibuko, 2006; Robinson \& Zinn, 2007; Walton \& Rusznyak, 2014). Opportunities for pre-service teachers to articulate their pedagogic reasoning would require that they consider the compelling grounds for choices teachers make about the most appropriate way to teach this content to these learners in this context. Drawing on insights from sociological studies of educational knowledge practices, Hugo (2013, p. 7) posed a set of key questions that "open out the basic levers of education" and show how they work. He cautioned that although the questions are common across all educational settings, appropriate answers need to be considered in context. Questions cover teacher choices about knowledge selection, and sequencing, and pacing, as well as the nature of classroom interactions between teacher and learners. Courses in ITE curricula may seek to equip teachers with strategies to teach learners who experience barriers to their learning (including special needs, a mismatch between home and learning languages, and poverty). While teachers need to understand the histories, struggles, priorities, learner diversities, and resourcing inequalities that still plague the education system, their obligation includes the provision of quality learning opportunities to all learners in front of them.

\section{Conceptualising WIL as a mechanism for creating coherence in ITE curricula}

Since Shulman (1987) developed his typology of teacher knowledge, ITE curricula have increasingly focused on providing prospective teachers with knowledge bases for teaching 
(Bertram \& Christiansen, 2012; Darling-Hammond \& Bransford, 2005). We have shown that the current legislation governing teacher education in South Africa also takes this approach. ITE curricula are typically designed as a collection of courses that provide students access to different bodies of knowledge. Although each course may be internally coherent with conceptual and skill progression over time, the different courses in ITE programmes tend to have a "notable absence of links" between them (Hoban, 2005, p. 2). Pre-service teachers are thus expected to make connections between and among the different components of their ITE curriculum. While some do, many do not. To those who are unable to figure out the ways different components may be used as grounds for decision-making, teaching may seem like a fragmented activity without an internal logic. An accumulation of unstructured classroom experiences during WIL would be insufficient to enable these students to access the logics that underpin teachers' practice.

Much has been written about a theory-practice divide in which concepts learnt in coursework remain separated from understanding and informing the classroom practices of teachers (Henning \& Gravett, 2011; Jeram \& Davids, 2020). When sessions of WIL are interspersed with sessions of coursework without attention to the iterative transfer of knowledge and reasoning between the two, this divide is entrenched (Walton \& Rusznyak, 2019). Without a mechanism for drawing insights together to inform thinking and judgement in relation to a particular problem-situation (like how best to teach a concept to learners in a specific context), knowledge for practice remains inert and fragmented. As Maton (2016, p. 9) explained, "[C]oncepts do nothing by themselves; their potential for knowledge-building is realised by actors." ITE curricula need to do more than provide prospective teachers with access to various bodies of knowledge. They need to provide opportunities for students to articulate their reasoning about what they do and why so that the grounds of that reasoning can be engaged with explicitly. Our argument here seeks to retain recognition of the value of theoretical perspectives in coursework but considers how principled knowledge, contextual factors, and the demands of the lessons' content knowledge can be recruited as grounds for justifying why certain choices in practice are more appropriate than others. A pedagogic reasoning approach in WIL can thus be a powerful mechanism that requires students to draw together learning from various parts of their ITE curricula.

\section{Implications for practice: How a pedagogic reasoning approach may be structured into WIL}

For students to become knowers who have both the knowledge and dispositions needed for the professional practice of teaching, organising sessions of WIL needs to entail more than a logistical exercise of allocating pre-service teachers to accessible schools with someone appointed to assess them against a checklist. An important purpose of WIL is to give preservice teachers ample opportunities to understand the many pedagogic choices teachers make in designing the lessons they teach. Developing their processes of thinking in practice does not happen automatically with undirected time in the classroom. School-based activities (including lesson observation and analysis, lesson preparation, and reflection on practice) 
need to alert student teachers to the less visible reasoning that teachers do in their daily work. To structure WIL in a way that not only gives students access to new knowledge but also shapes their gaze as developing knowers, two processes are necessary. First, students need to recognise teachers as knowers and their pedagogic reasoning in context needs to become more visible to students. Second, assessment of student competence in WIL needs to consider their performance as well as their ability to articulate the reasoning behind their choices.

We now consider three practical ways in which a pedagogic reasoning approach can be structured in WIL. We then consider some limitations and caveats of such an approach.

\section{A study of teachers' reasoning in recorded lessons}

As schools closed during the COVID-19 pandemic in 2020, organising practice-based learning opportunities for pre-service teachers became a national priority (Robinson \& Rusznyak, 2020). A team of teacher educators developed a nationally available online course, called Teacher Choices in Action to supplement WIL requirements. Using a "learning-frompractice" approach (DHET, 2015, p. 10), the course draws students' attention to key decisions all teachers make as they work with subject knowledge and learner diversity in their school contexts (Hugo, 2013). The module introduces students to fundamental decisions that all teachers make in every lesson. A series of tasks requires them to work through guided examples of pedagogic reasoning in action and look at these choices in recorded lessons relating to their own phase and subject specialisations. With guided lesson observations and task analysis, a study of practice from different perspectives prompts consideration of why some choices are more appropriate than others in response to the content taught, the needs of learners, and the contextual realities in which the teachers work. The research component of the Teacher Choices in Action project analyses whether, in using these key questions to undertake informed analysis of classroom practice, students' understanding of practice is more likely to move beyond a superficial description of visible classroom routines.

We have argued that courses that make up an ITE curriculum often focus on giving students access to different bodies of knowledge. It may be that assessment tasks draw students' attention to teacher choices, but these will generally be in relation to one aspect of teaching (e.g., choices informed by subject-specific pedagogy, or choices that are inclusive, or choices that are responsive to contextual priorities). An innovative approach offered by this course is the way in which it brings all these conceptual lenses to bear on the same set of lessons. Making the less visible parts of teacher thinking available to pre-service teachers is an important part of taking their gaze beyond that developed through their own experiences of schooling. When pre-service teachers view teachers as knowers who make reasoned choices in their teaching practices, this enables them to develop their own gaze as they learn to teach. 
Structured opportunities to articulate reasoning in WIL through lesson planning requirements

Guidelines for lesson planning have the potential to require pre-service teachers to draw on various bodies of knowledge as they conceptualise a series of lessons, thereby advancing a pedagogic reasoning approach in WIL. The lesson planning requirements are used repeatedly by students in different grades, with different content focus areas and in different school contexts. They serve as a significant framework that potentially guides the way that preservice teachers rationalise the design of their lessons (Rusznyak \& Walton, 2011).

The potential for articulation between WIL and knowledge from coursework, as well as the development of a specialist gaze, is undermined when pre-service teachers' lesson planning is regarded as an administrative task without due thought about the demands of content, the needs of learners, and the contextual possibilities that inform pedagogic decision-making. Articulating their pedagogic reasoning for the design of the lessons they teach transmits to students that there are compelling grounds for the choices teachers make about the most appropriate way to teach this content to these learners in this context. As part of the mentoring and assessment process, the grounds of their lesson design (not just the execution of its plan) can be probed.

\section{Valuing the articulation of reasoned practice in WIL assessment rubrics}

The criteria used to assess students' teaching conveys to them what aspects of their teaching is valued. When WIL assessment rubrics contain atomistic criteria in checklists, they advance a fragmented and technicist approach to evaluating teaching (Rusznyak \& Bertram, 2015). Student teachers score highly when lessons include desired components regardless of how appropriate that strategy is for the content taught. Vaguely defined levels of achievement such as 'excellent' or 'very good' obscure messages about what students are doing well, what they could be doing better, and how they could improve. In addition to dispositions and performance, the design of WIL assessment rubrics could convey to students that their articulation of reasoning for their pedagogic choices is also valued. When level descriptors make it clear that what is valued in teaching moves from normative protocols to informed decision-making and responsiveness to the learning dynamics in the classroom, pre-service teachers get the message that their reasoning matters for achievement and that there are grounds upon which some teaching decisions are better than others.

\section{Limitations of a pedagogic reasoning approach}

We have argued strongly for making the pedagogic reasoning which underpins teacher's pedagogic choices explicit in WIL. However, there are three limitations that we acknowledge. One is a conceptual limitation, another is related to curriculum, and the third is a practical consideration.

While scholars like Biesta (2015), Morrow (2007), Shalem (2014), and Shulman (1987), have noted the centrality of pedagogic reasoning in professional teaching, few have considered 
how teachers develop capacity for reasoned judgement. One notable attempt is the development of content representation (CoRes) structures proposed by Loughran et al., (2012). The conceptual tools provided by the Specialization dimension of Legitimation Code Theory may provide a useful framework to conceptualise pre-service teachers as knowers and pedagogic reasoning as a specialised gaze which is partly shaped by one's history, experiences, and dispositions and also through knowledge and interactions with "significant others" (Maton, 2014, p. 185). We recognise that there is more intellectual work and empirical research to be done in this regard.

A curriculum limitation to the development of pre-service teachers' capacity for pedagogic reasoning lies in their access to the theoretical tools provided through coursework. If an ITE curriculum offers practice-focused study only, students are denied access to principled grounds for reasoned judgment. While conceding that perceptions can be wrong, theoretical insights may be misunderstood and misapplied, and pedagogic reasoning may not always lead to good judgements. However, articulating one's reasoning opens possibilities for scrutiny and discussion about the appropriateness of choices in terms of a variety of considerations such as underpinning ethical stances, content knowledge, responsiveness to learner needs, and context. We maintain that reasoned practice is preferable to unthinking, uncritical assimilation into prevalent practices when these are ineffective and when they perpetuate exclusion or marginalisation. In this way, a pedagogic reasoning approach underpinned by principled knowledge potentially establishes conditions for educational transformation.

A practical limitation is that of enabling teachers who act as mentors in school to become aware of their own pedagogic reasoning and how to explicitly articulate it. There is much written on the tacit nature of teacher knowledge within the tradition that understands teaching as a craft that can be passed on through practice with limited explanation (Winch, 2017). For teachers who understand their work as a craft that is learned through experience, it will be difficult to articulate their own pedagogic reasoning to pre-service teachers. This limitation may be partially mitigated through guided analysis of recorded lessons and the pedagogic choices teachers make. Furthermore, there are ways in which WIL expectations and assessment can be structured so that students come to recognise the importance of articulating their own reasoning.

\section{Conclusion}

To enable pre-service teachers to develop more specialised teaching practices, WIL sessions need to provide them with more than opportunities to accumulate time in school-based placements and mimic prevalent practices. Learning to teach can be a hit-or-miss affair when the organisation of WIL is regarded primarily as a logistical matter of allocating student teachers to schools and ensuring that they spend sufficient time to meet policy requirements. The value of WIL would be greatly enhanced if pre-service teachers and their mentors are aware of both visible routines and the less visible reasoning that inform the pedagogic choices that teachers make. Expectations of students during WIL therefore needs to provide 
pre-service teachers with explicit, structured opportunities to consider how the teachers they observe enact their teaching and why. They also need to articulate the choices they make in the design and delivery of their own lessons. Without such a focus, the quality of learning through WIL remains focused on performance and contingent on each student's individual experiences. Furthermore, the opportunities to articulate their reasoning and have this recognised as part of how their teaching competence is assessed would signify its importance. We argue that structuring WIL as a space in which to recognise and engage in forms of pedagogic reasoning addresses some of the challenges of uneven quality of student learning identified in research on WIL in the South African context.

\section{Acknowledgements}

The authors are grateful to Dale Langsford for valuable input and support.

The Teacher Choices in Action module forms a part of the Teaching and Learning Development Capacity Improvement Programme (TLDCIP) that is implemented through a partnership between the Department of Higher Education and Training (DHET) and the European Union.

Lee Rusznyak acknowledges the ongoing support from the Unesco Chair Forum in Teacher Education for Diversity and Development.

\section{References}

Amin, N., \& Ramrathan, P. (2009). Preparing students to teach in and for diverse contexts: A learning to teach approach. Perspectives in Education, 27(1), 69-77.

Ball, D. L., Thames, M. H., \& Phelps, G. (2008). Content knowledge for teaching: What makes it special? Journal of Teacher Education, 59(5), 389-407.

Ball, D., \& Forzani, F. M. (2009). The work of teaching and the challenge of teacher education. Journal of Teacher Education, 60(5), 497-511.

Bernstein, B. (2000). Pedagogy, symbolic control, and identity. Rowman \& Littlefield Publishers.

Berry, A., Loughran, J., \& van Driel, J. (2008). Revisiting the roots of pedagogic content knowledge. International Journal of Science Education, 30(10), 1271-1279.

Bertram, C., \& Christiansen, I. M. (2012). Editorial. Journal of Education, 56, 1-16.

Bertram, C., Mthiyane, N., \& Mukeredzi, T. (2013). 'It will make me a real teacher': Learning experiences of part time PGCE students in South Africa. International Journal of Educational Development, 33(5), 448-456. 
Biesta, G. (2015). What is education for? On good education, teacher judgement and educational professionalism. European Journal of Education, 50(1),75-87.

Borello, L. (2019). Learning to teach in a situated learnership model of teacher education: A case study of the support provided by mentor teachers in the process of learning to teach (Unpublished M.Ed. research report). University of the Witwatersrand, Johannesburg, RSA.

Borg, M. (2004). The apprenticeship of observation. ELT Journal, 58(3), 274-276.

Christiansen, I. M., Österling, L., \& Skog, K. (2019). Images of the desired teacher in practicum observation protocols. Research Papers in Education. https://doi.org/10.1080/02671522.2019.1678064

Cochran-Smith, M., \& Lytle, S. (1999). Relationships of knowledge and practice: Teacher learning in communities. Review of Research in Teacher Education, 24, 249-306.

Council of Higher Education. (2010). Report on the National Review of Academic and Professional Programmes in Education, August. HE Monitor No. 11. Council of Higher Education.

De Lange, N., Khau, M., \& Athiemoolam, L. (2014). Teaching practice at a rural school 'And why should we go there?' South African Journal of Higher Education, 28(3), 748766.

Deacon, R. (2016). The initial teacher education research project. JET Education Services.

Department of Higher Education and Training. (2015). Revised Policy on the Minimum Requirements for Teacher Education Qualifications. Government Printer.

Dorovolomo, J. (2004). Teachers' practical theory: Personal articulation and implications for teachers and teacher education in the Pacific. Pacific Curriculum Network, 13(1/2), $10-16$.

Du Plessis, E. C., Marais, P., Van Schalkwyk, A., \& Weeks, F. (2010). Adapt or die: The views of Unisa student teachers on teaching practice at schools. Africa Education Review, 7(2), 323-341.

Duffy, G. G. (2005). Developing metacognitive teachers: Visioning and the expert's changing role in teacher education and professional development. In S. E. Israel, C. Collins Block, K. L. Bauserman \& K. Kinnucan-Welsch (Eds.), Metacognition in literacy learning (pp. 299-315). Routledge.

Evans, J. B. T. (2019). Hypothetical thinking: Dual processes in reasoning and judgement. Psychology Press. 
Gravett, S., Henning, E., \& Eiselen, R. (2011). New teachers look back on their university education: Prepared for teaching, but not for life in the classroom. Education as Change, 15, S123-S142.

Gravett, S., \& Ramsaroop, S. (2015). Bridging theory and practice in teacher education: Teaching schools-A bridge too far? Perspectives in Education, 33(1), 131-146.

Gravett, S., \& Jiyane, L. (2019). The practice learning experiences of student teachers at a rural campus of a South African university. South African Journal of Childhood Education, 9(1), a702. https://doi.org/10.4102/sajce.v9i1.702.

Hammerness, K., Darling-Hammond, L., Bransford, J, Berliner, D., Cochran-Smith, M., McDonald, M., \& Zeichner, K. (2005). How teachers learn and develop. In L. Darling-Hammond, \& J. Bransford (Eds.), Preparing teachers for a changing world: What teachers should learn and be able to do (pp. 358-389). Jossey-Bass.

Henning, E., \& Gravett, S. (2011). Pedagogical craft and its science: Janus-faced in preservice teacher education. Education as Change, 15(sup.1), S21-S33.

Hirst, P., \& Carr, W. (2005). Philosophy and education-A symposium. Journal of Philosophy of Education, 39(4), 615-632.

Hoban, G. F. (2005). Developing a multi-linked conceptual framework for teacher education design. In G. F. Hoban (Ed.), The missing links in teacher education design: Developing a multi-linked conceptual framework (pp. 1-15). Springer.

Horn, I. S. (2010). Teaching replays, teaching rehearsals, and re-visions of practice: Learning from colleagues in a mathematics teacher community. Teachers College Record, 112(1), 225-259.

Hugo, W. (2013). Cracking the code to educational analysis. Pearson.

Jeram, R., \& Davids, N. (2020). In support of practice-based teacher professional learning. South African Journal of Higher Education, 34(3), 112-127.

Korthagen, F. A. J. (2004). In search of the essence of a good teacher: Towards a more holistic approach in teacher education. Teaching and Teacher Education, 20, 77-97.

Korthagen, F. A. J. (2017). Inconvenient truths about teacher learning: Towards professional development 3.0. Teachers and Teaching, 23(4), 387-405.

Langsford, D. (2020). 'Those who can think, teach': The pedagogical reasoning of preservice teachers from different initial teacher education pathways. (Unpublished doctoral dissertation). University of the Witwatersrand, Johannesburg, RSA.

Lortie, D. (1975). School-teacher: A sociological study. The University of Chicago Press. 
Loughran, J. (2019). Pedagogical reasoning: The foundation of the professional knowledge of teaching. Teachers and Teaching, 25(5), 523-535.

Loughran, J., Berry, A., \& Mulhall, P. (2012). Understanding and developing science teachers' pedagogical content knowledge. Springer Science \& Business Media.

Maton, K. (2014). Knowledge and knowers: Towards a realist sociology of education. Routledge.

Maton, K. (2016). Building knowledge about knowledge-building. In K. Maton, S. Hood, \& S. Shay (Eds.) Knowledge building. Educational studies in Legitimation Code Theory (pp. 1-24). Routledge.

Matoti, S. N., \& Odora, R. J. (2013). Student teachers' perceptions of their experiences of teaching practice. Journal of Higher Education, 27(1), 126-143.

Mazibuko, N. J. L. (2006). Multicultural internship: Key to baptizing pre-service educators into a river of non-racialism and multiculturalism. Education as Change, 10(2), 6779.

Menkveld, H., Bitzer, E., \& Reddy, C. (2008). The practicum in pre-service teacher education: A survey of institutional practices. Southern African Review of Education with Education with Production, 14(1/2), 143-163.

Moodley, T., Sadeck, M., \& Luckay, M. (2018). Developing student teachers' professional knowledge (including Teaching practice) in the Further Education \& Training phase. In Y. Sayed, N. Carrim, A. Badroodien, Z. McDonald \& M. Singh (Eds.), Learning to teach in a post-apartheid South Africa (pp. 131-148). Sun Press.

Moosa, M. (2018). Promoting quality learning experiences in teacher education: What mentor teachers expect from pre-service teachers during teaching practice. The Independent Journal of Teaching and Learning, 13(1), 57-68.

Morrow, W. (2007). What is teachers' work? Journal of Education, 41, 1-20.

Mukeredzi, T., Mthiyane, C. C. N., \& Bertram, C. (2015). Becoming professionally qualified: The school-based mentoring experiences of part-time PGCE students. South African Journal of Education, 35(2), 1-9.

Nelson Mandela Foundation. (2005). Emerging voices: A report on education in South African rural communities. Human Sciences Research Council Press.

Nkambule, T., \& Mukeredzi, T. G. (2017). Pre-service teachers' professional learning experiences during rural teaching practice in Acornhoek, Mpumalanga Province. South African Journal of Education, 37(3), 1-9. 
Österling, L. (2021). inVisible theory in pre-service mathematics teachers' practicum tasks. Scandinavian Journal of Educational Research, 1-15. https://doi.org/10.1080/00313831.2021.1897874.

Ramsaroop, S. (2016). The potential of teaching schools in South Africa to enable learning for the teaching profession (Unpublished doctoral dissertation). University of Johannesburg, RSA.

Reeves, C., \& Robinson, M. (2014). Assumptions underpinning the conceptualisation of professional learning in teacher education. South African Journal of Higher Education, 28(1), 236-253.

Rembe, S., Shuma, J., Maposa, C., \& Musesengwe, E. (2016). Change theory: The teacher as reflective and change agent. In C. Okeke, J. Abogdia, E. Olusola Adu, M. van Wyk \& C. Wolhuter (Eds.), Learning to teach: A handbook for teaching practice (pp 32-48). Oxford.

Robinson, M. (2015). Teaching and learning together: The establishment of Professional Practice Schools in South Africa: A Research Report for the Department of Higher Education and Training. Stellenbosch University.

Robinson, M., \& Rusznyak, L. (2020). Learning to teach without school-based experience: Conundrums and possibilities in a South African context. Journal of Education for Teaching, 46(4), 517-527.

Robinson, M., \& Zinn, D. (2007). Teacher preparation for diversity at three South African universities. Journal of Education, 42(1), 61-81.

Rusznyak, L., \& Bertram, C. (2015). Knowledge and judgement for assessing student teaching: A cross-institutional analysis of teaching practicum assessment instruments. Journal of Education, 60, 31-61.

Rusznyak, L., \& Walton, E. (2011). Lesson planning guidelines for student teachers: A scaffold for the development of pedagogical content knowledge. Education as Change, 15(2), 271-285.

Rusznyak, L., \& Walton, E. (2017). Could practicum placements in contrasting contexts support the preparation of pre-service teachers for an envisaged inclusive education system? A South African study. International Journal in Disability, Development and Education, 64(3), 231-248.

Schön, D. A. (1987). Educating the reflective practitioner: Toward a new design for teaching and learning in the professions. Jossey-Bass. 
Shalem, Y. (2014). What binds professional judgement? The case of teaching. In M. Young \& J. Muller (Eds.), Knowledge, Expertise and the Professions (pp. 93-105). Routledge.

Shulman, L. S. (1987). Knowledge and teaching: Foundations of the new reform. Educational Researcher, 15(2), 14-44.

Silbert, P., \& Verbeek, C. (2016). Partnerships in action: Establishing a model of collaborative support to student and mentor teachers through a university-school partnership. Journal of Education, 64, 111-136.

South African Council for Educators (SACE). (2019). Professional Teaching Standards (Draft). https://www.sace.org.za/assets/documents/uploads/sace_31561-2020-10-12Professional\%20Teaching\%20Standards\%20Brochure.pdf.

Verloop, N., Van Driel, J., \& Meijer, P. (2001). Teacher knowledge and the knowledge base of teaching. International Journal of Educational Research, 35(5), 441-461.

Walton, E., \& Rusznyak, L. (2014). Affordances and limitations of a special school practicum as a means to prepare pre-service teachers for inclusive education. International Journal of Inclusive Education, 18(9), 957-974.

Walton, E. \& Rusznyak, L. (2019). Cumulative knowledge-building for inclusive education in initial teacher education. European Journal of Teacher Education, 1(43), 18-37. https://doi.org/10.1080/02619768.2019.1686480.

Winch, C. (2017). Teachers' know-how. A philosophical investigation. Wiley Blackwell. 